\title{
Ionic Liquid Mediated Conductive Polymers
}

\section{Yousef Haik*}

${ }^{*}$ Department of Mechanical Engineering, United Arab Emirates University, P O Box 17555, Al Ain, UAE

Room temperature ionic liquids (RTILs) are salts with melting points close or below room temperature, $30^{\circ} \mathrm{C}$. Most polymers in the industry have shown to display hydrophilic characteristics, which have had more scientists paying much attention for membrane electrolyte during the past few years. The first work to become published in the study for solid polymer electrolyte was carried out by Wright and coworkers $[1,2]$ and was devoted to the ionic nature for their conducting behavior. Scientists have used ionic liquids, also known as plasticizers, as organic solvents and supporting electrolytes in many fields due to their exceptional properties like high conductivity, non-volatility, non-flammability, etc. [3-8]. Due to the significant development of plasticizers to the conductivity, thermal and electrochemical properties of polymers, the merging of plasticizers into different polymers has been reported [9-11]. In order to overcome the brittleness of polymer films, the addition of plasticizers is important to improve flow and flexibility, and to increase toughness, to impact resistance of film coasting, and to prevent them from cracking during packaging and transportation $[12,13]$. The compatibility and permanence is normally based on the selection of plasticizer for a specified system, the amount needed for plasticization, and the desired physical properties of the films [14].

Ionic liquids when blended with polymers show a promising class of new materials with a bright technological future. The blends are now being used in application that are enabled by their presence, as well as in application where device or process performance outweighs their higher cost.

The main driving force to explore ionic liquids is the fact that these compounds have a very low vapor pressure, so that they are candidates to replace volatile organic solvents in organic reactions, because the properties of ionic liquids (miscibility with water and other solvents, dissolving ability, polarity, viscosity, density) can be tuned by an appropriate choice of the anion and the cation. Ionic liquids are often considered as designer solvents. These ionic liquids can also be used to immobilize transition metal catalysts in the liquid phase of biphasic catalytic reactions. Other applications include their use as solvents for extraction processes and as an electrolyte for batteries, fuel cells, and dye-sensitized solar cells. Also they are neutral organic compounds. Ionic liquid are a class of liquid salt that contain anions and cations. The ionic character means that some of the properties of the ionic liquid differ significantly from that of conventional organic liquids.

Polymeric microelectronic devices such as memory devices, sensors and fuel cells, require conductive polymers in its composition. Doping polymers with iodine and arsenic to modulate the electrical conductivity have been reported in recent years. However, doping non-conductive polymers with organic plasticizer to modulate their electrical conductivity just emerged in recent years. Ayesh et al. [15], reported doping poly (vinyl alcohol) (PVA) thin films with various ratios $(0-5 \% \mathrm{w} / \mathrm{w})$ of 1-methyl-3-n-decyl-imidazolium bromide ionic liquid [MDIM] (+)Br(-). PVA is a hydrophilic semi-crystalline polymer produced by polymerization of vinyl acetate monomer to form poly (vinyl acetate) (PVAc), and subsequent hydrolysis of PVAc to form PVA [16]. PVA is soluble in water. When formed as thin films, the properties of PVA are extremely affected by the molecular weight and the degree of hydrolysis [17]. The AC impedance measurements were conducted for a frequency range of $10-10^{6} \mathrm{~Hz}$ as a function of temperature between 298-425 K. The results showed that the resistivity of the thin film decreases as the dopant ratio increases. The results also showed that the film relaxation time decreases as the dopant ratio increases. Increasing the film temperature was found to decrease the resistivity of the films due to the increase in charge carrier concentration. The films activation energy is adjusted by tuning the dopant concentration in the blend.

Josh et al. [18], reported the electrical properties of polymer membrane made out of blending PVA, poly (acrylamide-co-acrylic acid) (PAA) and varying ratio $(0-5 \% \mathrm{w} / \mathrm{w})$ of sorbitol. It was observed that as the temperature increases, the resistivity decreases in general for polymer films. In addition, increasing the doping concentration decreases the resistivity. The results showed a systematic decrease in the resistivity with the increase of doping concentration. The activation energy decreases with increasing the sorbitol concentration. The relaxation time decreases with temperature. At high frequency range, the conductivity is dominated by the ionic conduction process in the bulk of the polymer electrode [19-21].

The effect of ionic liquid on the polymer segmental and conductivity depends on the specific nature of the ionic liquid, including viscosity, dielectric constant and polymer-ionic liquid interaction.

A key application for the new classes of conductive polymers lies in the polymeric memory devices. A polymeric memory device generally consists of sandwiched conductive terminals, semiconducting material and storage element (usually nanoparticles). Haik [21] employed the conductive characteristics of polymeric blends made out of PVA, PAA and glycerol ionic liquid as semiconductors. Single wall carbon nanotubes were used as storage element. Double sweep capacitancevoltage tests were carried out to identify memory properties of the organic semiconductor devices. The $2 \%$ mixture of the ionic liquids glycerol was used. When CNT was introduced, it gave a significant window gate of $\pm 20 \mathrm{~V}$, indicating that there is no leak in the system.

The ionic liquids as dopant to modulate conductivity in nonconductive polymers are promising and it is anticipated that new applications will emerge that takes advantages of these inexpensive conductive polymers.

\section{References}

1. Fenton DE, Parker J, Wright P (1973) Complexes of Alkali Mrtal Ions with Poly (ethylene Oxide). Polymer 14: 589.

${ }^{*}$ Corresponding author: Yousef Haik, Department of Mechanical Engineering United Arab Emirates University, P O Box 17555, Al Ain, UAE, E-mail: yhaik@uaeu.ac.ae

Received October 30, 2012; Accepted November 01, 2012; Published November 03, 2012

Citation: Haik Y (2012) Ionic Liquid Mediated Conductive Polymers. J Appl Mech Eng 2:e112. doi:10.4172/2168-9873.1000e112

Copyright: @ 2012 Haik Y. This is an open-access article distributed under the terms of the Creative Commons Attribution License, which permits unrestricted use, distribution, and reproduction in any medium, provided the original author and source are credited. 
2. Wright PV (1975) Electrical Conductivity in Ionic Complexes of Poly (ethylene Oxide). Brit Polym J 7: 319-327.

3. Singh B, Sekhon SS (2005) lon conducting behaviour of polymer electrolytes containing ionic liquids Chem Phys Lett 414: 34-39.

4. Huddleston JG, Rogers RD (1998) Room temperature ionic liquids as nove media for 'clean' liquid-liquid extraction. Chem Commun 1765-1776.

5. Matsumi N, Sugai K, Miyake M, Ohno H (2006) Polymerized lonic Liquid via Hydroboration Polymerization as Single Ion Conductive Polymer Electrolytes. Macromolecules 39: 6924-6927.

6. Sekhon SS, Lalia BS, Kim CS, Lee WY (2007) Advanced Polymer for Emerging Technologies. Macromol Symp 249: 5-23.

7. Jiang H, Fang SB (2006) New composite polymer electrolytes based on room temperature ionic liquids and polyether. Polym Adv Technol 17: 494-499.

8. Ogihara W, Sun JZ, Forsyth M, MacFarlane DR, Yoshizawa M, et al. (2004) Ionic conductivity of polymer gels deriving from alkali metal ionic liquids and negatively charged polyelectrolytes. Electrochimica Acta 49: 1797-1801.

9. Kim KS, Park SY, Choi S, Lee H (2006) lonic liquid-polymer gel electrolytes based on morpholinium salt and PVdF (HFP) copolymer. J Power Sources 155 $385-390$

10. Shin JH, Henderson WA, Tizzani C, Passerini S, Jeong SS, et al. (2006) Characterization of Solvent-Free Polymer Electrolytes Consisting of Ternary PEO-LiTFSI-PYR14 TFSI. J Electrochem Soc 153: A1649-A1654.

11. Cheng H, Zhu CB, Huang B, Lu M, Yang Y (2007) Synthesis and electrochemical characterization of PEO-based polymer electrolytes with room temperature ionic liquids. Electrochim Acta 52: 5789-5794.

12. Aydinli M, Tutas M (2000) Water Sorption and Water Vapour Permeability Properties of Polysaccharide (Locust Bean Gum) Based Edible Films. Food Sci Technol 33: 63-67.
13. Barreto PLM, Pires ATN, Soldi V (2003) Thermal degradation of edible films based on milk proteins and gelatin in inert atmosphere. Polym Degrad Stab 79: $147-152$

14. Cheng LH, Karim AA, Seow CC (2006) Effects of Water-Glycerol and WaterSorbitol Interactions on the Physical Properties of Konjac Glucomannan Films. J Food Sci 71: E62-E67.

15. Ayesh Al, Mohsin MA, Haik MY, Haik Y (2012) Investigations on electrical properties of poly(vinyl alcohol) doped with 1-methyl-3-n-decyl-imidazolium bromide ionic liquid. Current Appl Phys 12: 1223-1228.

16. Mansur HS, Sadahira CM, Souza AM, Mansur AAP (2008) FTIR spectroscopy characterization of poly (vinyl alcohol) hydrogel with different hydrolysis degree and chemically crosslinked with glutaraldehyde Mater Sci Eng 28: 539-548.

17. Pal K, Banthia AK, Majumdar DH (2006) Polyvinyl Alcohol-Gelatin Patches of Salicylic Acid: Preparation, Characterization and Drug Release Studies. J Biomat Appl 21: 75.

18. Josh V, Haik MY, Ayesh Al, Mohsin MA, Haik Y (2012) Electrical properties of sorbitol-doped poly(vinyl alcohol)-poly(acrylamide-co-acrylic acid) polymer membranes. J Appl Poly Sci

19. Alexy P, Bakos D, Hanzelova S, Kukolikova L, Kupec J, et al. (2003) Poly(vinyl alcohol)-collagen hydrolysate thermoplastic blends: I. Experimental design optimisation and biodegradation behavior. Polymer Testing 22: 801-809.

20. Chiellini E, Cinelli P, Fernandes EG, Kenawy ES, LAzzeri A (2006) Gelatinbased blends and composites. Morphological and thermal mechanical characterization Biomacromolecules 2: 806.

21. Haik M (2012) Conductive Polymer Blends and Their Use in Memory Devices. 